\title{
GT2013-95565
}

\section{EVALUATION OF REDUCED KINETICS IN SIMULATION OF GASIFIED BIOMASS GAS COMBUSTION}

\author{
Xiaoxiang Zhang*, Nur Farizan Munjat, Jeevan Jayasuriya, Reza Fakhrai, Torsten Fransson \\ Department of Energy Technology, KTH- Royal Institute of Technology \\ 10044, Stockholm, Sweden \\ Email: Xiaoxiang.Zhang@energy.kth.se, Nur-Farizan.Munajat@energy.kth.se, \\ Jeevan.Jayasuriya@energy.kth.se, Reza.Fakhrai@energy.kth.se, Torsten.Fransson@energy.kth.se
}

\section{ABSTRACT}

It is essentially important to use appropriate chemical kinetic models in the simulation process of gas turbine combustion. To integrate the detailed kinetics into complex combustion simulations has proven to be a computationally expensive task with tens to thousands of elementary steps. It has been suggested that an appropriate simplified kinetics which are computationally efficient could be used instead. Therefore reduced kinetics are often used in CFD simulation of gas turbine combustion. At the same time, simplified kinetics for specific fuel and operation conditions need to be carefully selected to fulfill the accuracy requirements. The applicability of several simplified kinetics for premixed Gasified Biomass Gas (GBG) and air combustion are evaluated in this paper.

The current work is motivated by the growing demand of gasified biomass gas (GBG) fueled combustion. Even though simplified kinetic schemes developed for hydrocarbon combustions are published by various researchers, there is little research has been found in literature to evaluate the ability of the simplified chemical kinetics for the GBG combustion. The numerical Simulation tool "CANTERA" is used in the current study for the comparison of both detailed and simplified chemical kinetics. A simulated gas mixture of $\mathrm{CO} / \mathrm{H}_{2} / \mathrm{CH}_{4} / \mathrm{CO}_{2} / \mathrm{N}_{2}$ is used for the current evaluation, since the fluctuation of GBG components may have an unpredictable influence on the simulation results. The laminar flame speed has an important influence with flame stability, extinction limits and turbulent flame speed, here it is chosen as an indicator for validation. The simulation results are compared with the experimental data from the previous study which is done by our colleagues. Water vapour which has shown a dilution effect in the experimental study are also put into concern for further validation. As the results indicate, the reduced kinetics which are developed for hydrocarbon or hydrogen combustion need to be highly optimized before using them for GBG combustion. Further optimization of the reduced kinetics is done for GBG and moderate results are achieved using the optimized kinetics compared with the detailed combustion kinetics.

\section{INTRODUCTION}

The utilization of Gasified Biomass Gas (GBG) fuel for traditional combustion engine such as gas turbine can potentially diminish the reliance on petroleum-based fuel and reduces the $\mathrm{CO}_{2}$ emission, which has become a promising and economic solution for environmental pollution and energy crisis in past decades [1]. As the GBG fuels are expected to be used in gas turbines, an adequate understanding of its fundamental combustion characteristics is required to guarantee the performance of power generation. It is necessarily required to improve the current combustor which is used for natural gas combustion to meet the requirements of GBG combustion. The fundamental combustor operability criteria must be satisfied regardless of the fuel that is being utilized by the gas turbine are robustness to autoignition, flashback, emissions compliance (NOx, CO, UHC, and smoke), acceptable combustion dynamic pressures, and lean blowout [2].

GBG fuels consist preliminary of $\mathrm{H}_{2}$ and $\mathrm{CO}$ as combustible substance. Smaller amounts of $\mathrm{CH}_{4}$ and other higher hydrocarbons are also detected in most GBG, as well as some other diluent gases like $\mathrm{N}_{2}, \mathrm{CO}_{2}$ and $\mathrm{H}_{2} \mathrm{O}$. The specific composition of a typical GBG fuel varies with the biomass source and processing techniques [3]. Therefore the numerical study is essential when studying GBG combustion characteristics with the possibility to provide information for 
"flexible" fuel composition and various operation conditions [4-6].

It is essentially important to choose an appropriate chemical kinetic model in the simulation process of gas turbine combustion. $\mathrm{CO} / \mathrm{H}_{2} / \mathrm{O}_{2}$ kinetic models which are the fundamental systems of all hydrocarbon combustion chemistry have been studied in details [7-9] and considered to be reasonably well established and understood [10,11]. Detailed kinetics for syngas (mainly $\mathrm{H}_{2} / \mathrm{CO}$ mixture combustion) are developed constantly in the past decade as a result of interest in gas turbine utilization. Marcos and Frederick [10] reviewed several proposed $\mathrm{H}_{2} / \mathrm{CO}$ kinetic changes based on recent experimental data. Numerical calculation of laminar flame speed for syngas were done by Ouimette and Seers [12] using GRI 3.0 detailed kinetic and CHEMKIN PREMIX code as simulation program. The composition obtained from wood residues $\left(\mathrm{CH}_{4} / \mathrm{CO} / \mathrm{CO}_{2} / \mathrm{C}_{2} \mathrm{H}_{4} / \mathrm{C}_{2} \mathrm{H}_{6}\right.$ mixture $)$ were used and results were compared with methane over a range of equivalence ratio, initial temperature and pressure.

Although the detailed kinetics for GBG combustion are developed constantly with recent experimental data, to integrate the detailed chemical kinetics into complex combustion simulations has proven to be a computationally expensive task [13-15]. It has been suggested that appropriate simplified kinetics which are computationally efficient could be used instead in complex fluid dynamic models to provide adequate predictions $[4,16,17]$. The simplified kinetics for specific fuel and operation conditions need to be carefully selected, since they are only valid over limited operating ranges and cannot account for all of the possible combustion phenomenon $[18,19]$. Westbrook and Dryer derived 1- and 2- steps simplified reaction kinetics for hydrocarbon fuels [7] and are widely used in the simulation of industrial combustors. Another well-known simplified kinetic is developed by Jones and Lindstedt [20] with 4-step simplified reaction by including two reactions for hydrocarbon oxidation.

In the past decade, there has been attempts to develop simplified kinetics for GBG fuels to fulfill the requirement of CFD simulation. The simplified reaction kinetics from Westbrook-Dryer and Jones-Lindstedt are optimized by A. Cuoci et al. [21] with comparison to a detailed kinetic in laminar diffusive counter-flow flames. P. Boivin et al. [4] developed a four-step reduced mechanism for syngas $\left(\mathrm{CO} / \mathrm{H}_{2}\right)$ combustion based on Quasi-Steady State Approximation (QSSA). The kinetic was tested with detailed kinetics and experimental data under various conditions. A moderate agreement is achieved between the detailed kinetic and the reduced version. However, the modifications are needed to achieve better agreements between kinetic calculations and experimental measurements. A syngas burner for gas turbines is simulated in the CFD program by Abdallah Abou-Taouk [3] with the reaction kinetic which is optimized for methane-air combustion.

Laminar flame speed is one of the essential parameters to characterize the combustion behavior of GBG as it contains information on reactivity, diffusivity and exothermicity
$[1,5,6,12,22-25]$. For the kinetic simulation, laminar flame speed is a fundamental target for validating reaction dynamic models as it is always used to predict flashback, blow off, flame stability and flame propagation in practice. The flame speed characteristics of syngas $\left(\mathrm{H}_{2} / \mathrm{CO}\right)$ are evaluated by $\mathrm{N}$. Bouvet et al. [26] using straight cylindrical burners. B. Yan et al. [5] measured adiabatic laminar flame speed of four compositions of $\mathrm{GBG}\left(\mathrm{CO} / \mathrm{CO}_{2} / \mathrm{H}_{2} / \mathrm{CH}_{4} / \mathrm{N}_{2}\right)$ at atmospheric pressure using the heat flux method and the results were compared with GRI 3.0 kinetic simulation. The influence the water vapour presence in the fuel stream on the laminar flame speed of $\mathrm{H}_{2} / \mathrm{CO}$ mixture combustion was reported by Das et al.[23] and the experimental data of laminar flame speed of GBG $\left(\mathrm{CO} / \mathrm{H}_{2} / \mathrm{CH}_{4} / \mathrm{CO}_{2} / \mathrm{N}_{2}\right)$ concerning $\mathrm{H}_{2} \mathrm{O}$ and Tar influences are published by co-authors of this paper. [1].

The objective of the current work is to evaluate the acceptability of appropriate simplified chemical kinetics instead of detailed chemical kinetics of GBG fuel combustion. The simplified kinetics that have been developed and optimized by various researchers are compared with detailed kinetics and experimental data for laminar flame speed predictions. A simulated gas mixture of $\mathrm{CO} / \mathrm{H}_{2} / \mathrm{CH}_{4} / \mathrm{CO}_{2} / \mathrm{N}_{2}$ is used for the current evaluation, since the fluctuation of $\mathrm{GBG}$ components may have an unpredictable influence on the simulation results.

\section{SIMPLIFIED CHEMICAL KINETICS}

There is few simplified kinetic which are specially developed for GBG combustion [4,10]. In most CFD simulations of combustion processes, a simplified reaction kinetic of methane combustion or hydrogen/carbon-monoxide combustion is generally used to represent chemical reaction process.

\section{The Westbrook and Dryer reaction kinetics (WD)}

The WD model for methane combustion consists of two reactions which are shown in Table 1 as $\mathrm{R} 1$ and $\mathrm{R} 2$. The simplified model is commonly used for natural gas combustion simulation in industrial applications. The WD reaction kinetic is originally developed by studying the high temperature oxidation reaction under fuel lean conditions in a turbulent flow reactor. The one-step simplified reaction is developed for hydrocarbon oxidation, and later the reverse reaction step for $\mathrm{CO}_{2}$ decomposition is introduced to refine the prediction for temperature and pressure dependence of the $\mathrm{CO} / \mathrm{CO}_{2}$ equilibrium.

As the GBG fuel consists of mostly hydrogen and carbonmonoxide, the assumption of pure $\mathrm{CO} / \mathrm{H}_{2}$ mixture combustion is often adopted in gas turbine simulation for GBG fuels. A set of simplified kinetic with $\mathrm{CO}$ and $\mathrm{H}_{2}$ oxidation is directly derived from Westbrook-Dryer kinetic with reactions $\mathrm{R} 2$ and $\mathrm{R} 3$ in Table 1 . In the $\mathrm{CO} / \mathrm{H}_{2}$ simulation, $\mathrm{H}_{2}$ oxidation is put into concern instead of $\mathrm{CH}_{4}$. Table 1 presents the reaction steps written in four irreversible steps as well as the calculation parameters for two approaches. The reversible reaction is derived into two irreversible reactions with the reverse reaction expression calculated as below: 
Table 1. Reaction rate equations and parameters from Westbrook-Dryer Kinetic

\begin{tabular}{|c|c|c|c|c|c|c|}
\hline No & Reactions & $A$ & $\beta$ & $E_{a}$ & Reaction Orders & ref \\
\hline R1 & $\mathrm{CH} 4+1.5 \mathrm{O} 2 \rightarrow \mathrm{CO}+2 \mathrm{H} 2 \mathrm{O}$ & $1.590 \times 10^{13}$ & 0 & 47800 & {$[\mathrm{CH} 4]^{0.7}[\mathrm{O} 2]^{0.8}$} & [27] \\
\hline $\mathrm{R} 2$ & $\mathrm{CO}+0.5 \mathrm{O} 2 \rightarrow \mathrm{CO} 2$ & $3.980 \times 10^{14}$ & 0 & 40700 & {$[\mathrm{CO}][\mathrm{O} 2]^{0.25}[\mathrm{H} 2 \mathrm{O}]^{0.5}$} & [27] \\
\hline $\mathrm{R} 2 \mathrm{r}$ & $\mathrm{CO} 2 \rightarrow \mathrm{CO}+0.5 \mathrm{O} 2$ & $5.000 \times 10^{8}$ & 0 & 40700 & {$[\mathrm{CO} 2]$} & [28] \\
\hline R3 & $\mathrm{H} 2+0.5 \mathrm{O} 2 \rightarrow \mathrm{H} 2 \mathrm{O}$ & $9.870 \times 10^{11}$ & 0 & 7400 & {$[\mathrm{H} 2][\mathrm{O} 2]$} & [7] \\
\hline R4 & $\mathrm{CO}+0.5 \mathrm{O} 2 \rightarrow \mathrm{CO} 2$ & $4.090 \times 10^{13}$ & 0 & 31700 & {$[\mathrm{CO}][\mathrm{O} 2]^{0.25}[\mathrm{H} 2 \mathrm{O}]^{0.5}$} & [21] \\
\hline $\mathrm{R} 4 \mathrm{r}$ & $\mathrm{CO} 2 \rightarrow \mathrm{CO}+0.5 \mathrm{O} 2$ & $4.450 \times 10^{9}$ & 0 & 41300 & {$[\mathrm{CO} 2]$} & [21] \\
\hline R5 & $\mathrm{H} 2+0.5 \mathrm{O} 2 \rightarrow \mathrm{H} 2 \mathrm{O}$ & $1.097 \times 10^{11}$ & 0 & 6900 & {$[\mathrm{H} 2]^{0.87}[\mathrm{O} 2]^{1.10}$} & [21] \\
\hline R6 & $\mathrm{CH} 4+1.5 \mathrm{O} 2 \rightarrow \mathrm{CO}+2 \mathrm{H} 2 \mathrm{O}$ & $1.400 \times 10^{10}$ & -0.062 & 27900 & {$[\mathrm{CH} 4]^{0.5}[\mathrm{O} 2]^{1.066}$} & [3] \\
\hline R7 & $\mathrm{CO}+0.5 \mathrm{O} 2 \leftrightarrow \mathrm{CO} 2$ & $7.380 \times 10^{11}$ & 0.215 & 18300 & {$[\mathrm{CO} 2][\mathrm{O} 2]^{0.5}$} & [3] \\
\hline
\end{tabular}

- $\quad$ Units used above: $\mathrm{cm}, \mathrm{s}$, cal, mol, and $\mathrm{K}$

$$
r_{b}=\frac{k_{f}}{K_{e q} \cdot(R T)^{-\sum_{i=1}^{N S} n_{i}}} \prod_{i=1}^{N S} C_{i}^{v_{b, i}}
$$

Where $n_{i}$ is the stoichiometric coefficient of each species in the reaction, $v_{b, i}$ is the order in the reverse reaction and can be derived from the order of the forward reaction and from the stoichiometric coefficient as: $v_{b, i}=v_{f, i}+n_{i}$. Instead of the original reaction kinetic that was developed by Westbrook and Dryer, the optimized kinetics from the original WD set are constantly proposed to meet the different requirements. However, there are only few of them are developed for GBG fuels. An optimized kinetic for syngas $\left(\mathrm{CO} / \mathrm{H}_{2}\right)$ combustion is proposed by A. Cuoci et al. [21] based on nonlinear regression (R4 and R5). The optimized kinetic was applied for the simulation of a turbulent diffusion jet flame and the accuracy of temperature prediction was improved dramatically. Another approach of optimization is proposed by Franzelli et al. [29] by introducing correction functions for reaction rates. The same approach is adopted by Abdallah et al. and a 3-step irreversible reaction kinetic for methane combustion is used in CFD simulation of a syngas burner for gas turbine (R6 and R7). The kinetic has been optimized with detailed kinetics for perfectly stirred reactor [3].

\section{The Jones-Lindstedt reaction kinetics (JL)}

Another set of commonly used simplified reaction kinetic was proposed by Jones and Lindstedt (1988) by studying premixed and non-premixed flames of alkane hydrocarbons. The breakdown of hydrocarbon is derived into two reactions: R8 and R9 in Table2. R8 is mainly dominant at fuel-lean conditions whereas R9 is important at fuel rich conditions. The water-gas-shift reaction and the oxidation of hydrogen are included in the simplified reaction kinetics as reactions R10 and R11.

The original reverse reaction of hydrogen oxidation that was proposed by Jones\&Lindstedt involves negative reaction orders that might cause numerical problems, and therefore derived into two irreversible reactions using Eq.1.

As the hydrogen and carbon monoxide oxidation are considered in the first place, the JL kinetics are considered to predict the $\mathrm{CO}$ concentration under fuel lean conditions more accurately. Optimization for original JL kinetics is done with various approaches. A. Cuoci [21] proposed a set of optimized parameters based on original JL kinetic for syngas $\left(\mathrm{CO} / \mathrm{H}_{2}\right)$ combustion (R12 and R13).

\section{DETAILED KINETICS AND EXPERIMENT DATA}

Two detailed kinetics are selected for current laminar flame speed calculation. GRI-Mech 3.0 kinetic [30] is optimized for natural gas combustion and is widely used for combustion simulation. The kinetic includes 53 species and 325 reactions. The laminar flame speeds validation for GRI-Mech 3.0 kinetic is carried with different fuel gases including methane-air, H2air, $\mathrm{CO}-\mathrm{H}_{2}$ and other hydrocarbons. Another detailed kinetics used here was developed by UC San Diego [31] which is designed to focus on conditions relevant to the flames, high temperature ignition and detonations. The San Diego kinetic is used in the recent work for the optimization of simplified kinetic for syngas $\left(\mathrm{CO} / \mathrm{H}_{2}\right)$ combustion [4] and is reported to have good agreements for the combustion of diluted syngas mixtures[2] .

Table 2. Reaction rate equations and parameters from Jones-Lindstedt Kinetic

\begin{tabular}{|c|c|c|c|c|c|c|}
\hline No & Reactions & $A$ & $\beta$ & $E_{a}$ & Reaction Orders & ref \\
\hline R8 & $\mathrm{CH} 4+0.5 \mathrm{O} 2 \rightarrow \mathrm{CO}+2 \mathrm{H} 2$ & $7.820 \times 10^{13}$ & 0 & 30000 & {$[\mathrm{CH} 4]^{0.5}[\mathrm{O} 2]^{1.25}$} & [20] \\
\hline R9 & $\mathrm{CH} 4+\mathrm{H} 2 \mathrm{O} \rightarrow \mathrm{CO}+3 \mathrm{H} 2$ & $3.000 \times 10^{11}$ & 0 & 30000 & {$[\mathrm{CH} 4][\mathrm{H} 2 \mathrm{O}]$} & [20] \\
\hline R10 & $\mathrm{H} 2+0.5 \mathrm{O} 2 \rightarrow \mathrm{H} 2 \mathrm{O}$ & $1.209 \times 10^{18}$ & -1 & 40000 & {$[\mathrm{H} 2]^{0.25}[\mathrm{O} 2]^{1.5}$} & [20] \\
\hline R10r & $\mathrm{H} 2 \mathrm{O} \rightarrow \mathrm{H} 2+0.5 \mathrm{O} 2$ & $7.060 \times 10^{17}$ & -0.870 & 97900 & {$[\mathrm{H} 2]^{-0.75}[\mathrm{O} 2][\mathrm{H} 2 \mathrm{O}]$} & [20] \\
\hline R11 & $\mathrm{CO}+\mathrm{H} 2 \mathrm{O}<=>\mathrm{CO} 2+\mathrm{H} 2$ & $2.750 \times 10^{12}$ & 0 & 20000 & {$[\mathrm{CO}][\mathrm{H} 2 \mathrm{O}]$} & [20] \\
\hline R12 & $\mathrm{H} 2+0.5 \mathrm{O} 2 \rightarrow \mathrm{H} 2 \mathrm{O}$ & $1.050 \times 10^{17}$ & -1 & 37700 & {$[\mathrm{H} 2]^{0.33}[\mathrm{O} 2]^{1.4}$} & [21] \\
\hline $\mathrm{R} 12 \mathrm{r}$ & $\mathrm{H} 2 \mathrm{O} \rightarrow \mathrm{H} 2+0.5 \mathrm{O} 2$ & $6.020 \times 10^{18}$ & -0.870 & 94000 & {$[\mathrm{H} 2]^{-0.75}[\mathrm{O} 2][\mathrm{H} 2 \mathrm{O}]$} & [21] \\
\hline R13 & $\mathrm{CO}+\mathrm{H} 2 \mathrm{O}<=>\mathrm{CO} 2+\mathrm{H} 2$ & $2.630 \times 10^{13}$ & 0 & 18500 & {$[\mathrm{CO}][\mathrm{H} 2 \mathrm{O}]$} & [21] \\
\hline
\end{tabular}

- $\quad$ Units used above: $\mathrm{cm}, \mathrm{s}$, cal, mol, and $\mathrm{K}$ 
The experimental data used for the current evaluation are from the previously study on the experimental investigation of the laminar flame speed of GBG/air combustion published by co-authors of this paper. The experiment setup is shown in Fig. 1 .

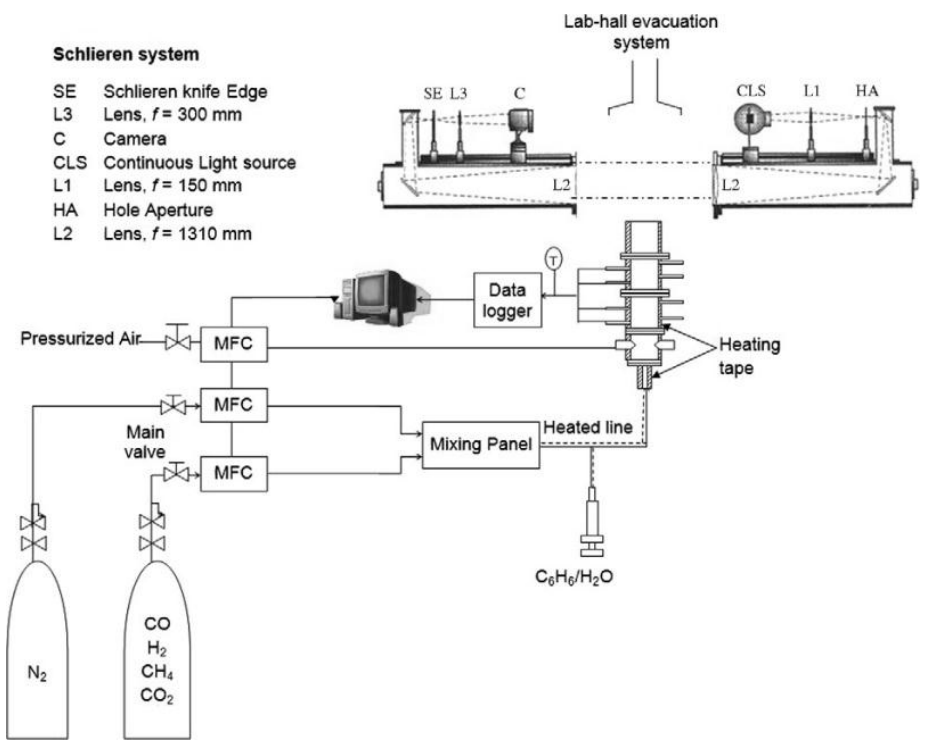

Fig. 1. Scheme of the experiment setup [1]

The laminar flame speed is measured on a basis of an areaweighted average laminar flame speed. The calculation is done through the mass conservation:

$$
S_{b} \rho_{b}=S_{u} \rho_{u} \rightarrow S_{u}=\frac{\dot{m}}{\rho_{u} A_{b}}=\frac{\dot{v}}{A_{b}}
$$

where $S_{u}$ is the unburned mixture flow speed and $\dot{v}$ is the volumetric flow rate of the unburned mixture. $S_{b}$ and $\rho_{b}$ are the flame speed and the burned gas density. A more detailed explanation regarding the laminar flame speed measurements can be found in [32].

The experiment used $\mathrm{CO} / \mathrm{H}_{2} / \mathrm{CH}_{4} / \mathrm{CO}_{2}$ and $\mathrm{N}_{2}$ mixture as a simulated gas of GBG fuels which the composition is shown in Table 3. The fuel mixture and air flow rates are controlled and

Table 3. The compositions and properties of the original mixtures

\begin{tabular}{ll}
\hline Gas components & Volumetric fraction (\%) \\
\hline $\mathrm{CO}$ & $25 \pm 3.5$ \\
$\mathrm{H}_{2}$ & $12.5 \pm 3.5$ \\
$\mathrm{CH}_{4}$ & $2.5 \pm 3.5$ \\
$\mathrm{CO}_{2}$ & $10 \pm 3.5$ \\
$\mathrm{~N}_{2}$ & $50 \pm 3.5$ \\
\hline
\end{tabular}

\begin{tabular}{ll}
\hline No. & Included Reactions \\
\hline WD1 & R1, R2, R2r \\
WD2 & R2, R2r, R3 \\
WD3 & R1, R4, R4r, R5 \\
JL1 & R8, R9, R10, R10r, R11 \\
JL2 & R8, R9, R12, R12r, R13 \\
\hline
\end{tabular}

Table 4. Selected reaction sets of simplified kinetics measured by mass flow controllers (MFC) before being introduced to the burner respectively. Two flows are mixed rapidly using a mixing panel. Downstream the mixing point, the liquid $\mathrm{H}_{2} \mathrm{O}$ was injected precisely via a syringe pump into the heated fuel mixture stream.

The evaluation of both simplified and detailed kinetics is done with an open-source combustions simulation software CANTERA [34] with an adiabatic free propagating flame code for laminar flame speed calculation. The laminar flame speed is achieved with a grid number around 300 to ensure the final result is converged. The selected sets of simplified kinetics with specific reactions are shown in Table 4.

\section{RESULT AND DISCUSSION Prediction of methane/air combustion}

As most of kinetics are optimized for natural gas combustion, the calculation of methane/air flame speed at several equivalence ratios are done under atmospheric pressure and an inlet fuel temperature of $298 \mathrm{~K}$ to compare with experiment data. The estimation uncertainty of experimental measurements is $3.7 \%$.

The result is shown in Fig. 2. The best agreement with experiment data is given by GRI-Mech 3.0. It is expected as it contains larger number of reactions. A slight over-prediction of laminar flame speed can be explained as the adiabatic flame approximation which is used in the simulation process. A quite similar result is achieved using San Diego kinetic with a variation of $4.3 \%$.

When considering two simplified kinetics, an overestimation of laminar flame speed is found in JL1 kinetic as WD1 kinetic tends to under-predict the flame speed in the fuel-lean region. However, as the flame moves towards fuelrich side, the JL1 kinetic is generally able to catch the bellshape curve which is shown by experimental data and detailed kinetics. The WD1 at the same time fails to predict the laminar flame speed in the fuel-rich region. The result is expected as the WD1 kinetic is only validated for the fuel-lean condition, as the JL1 kinetic is believed to be suitable for both the fuel-lean region and the moderate fuel-rich region.

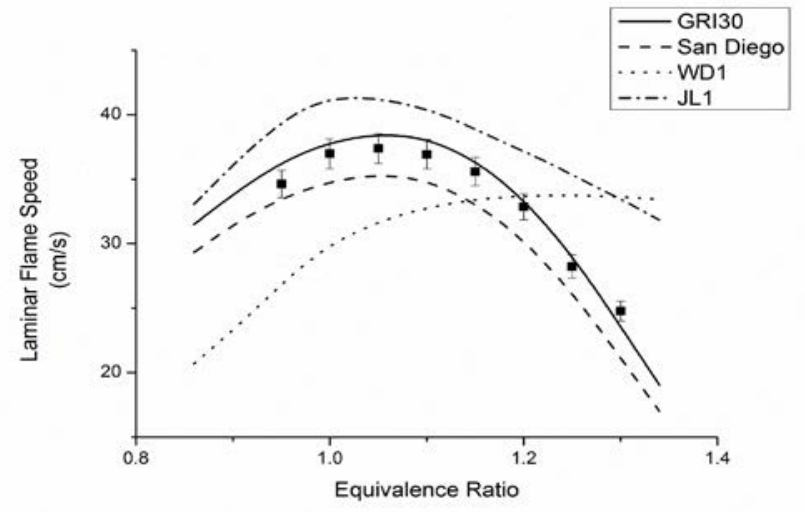

Fig. 2 Laminar flame speed of methane/air flame at $\mathrm{P}=1 \mathrm{~atm}, \mathrm{~T}_{\mathrm{in}}=298 \mathrm{~K}$ as function of equivalence ratio; Lines represent the calculation results achieved from chemical kinetics; Dots represent the experimental measurements. 


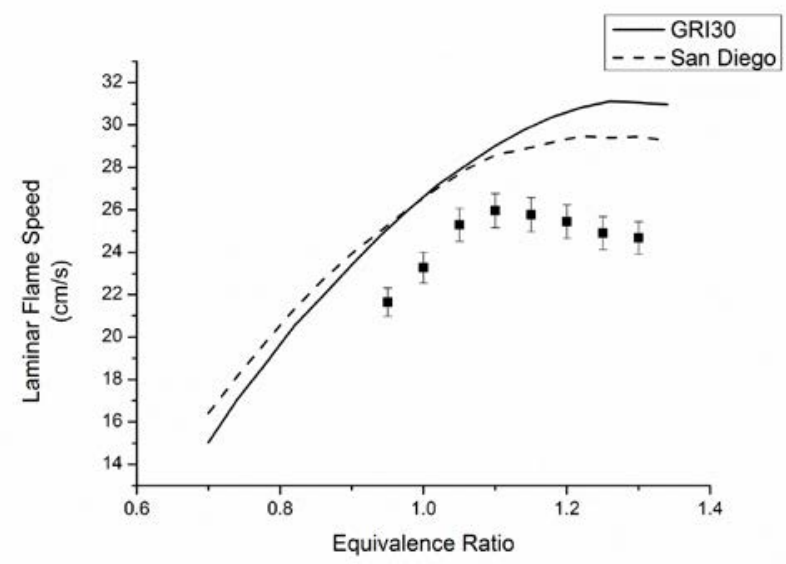

(a) Detailed kinetics

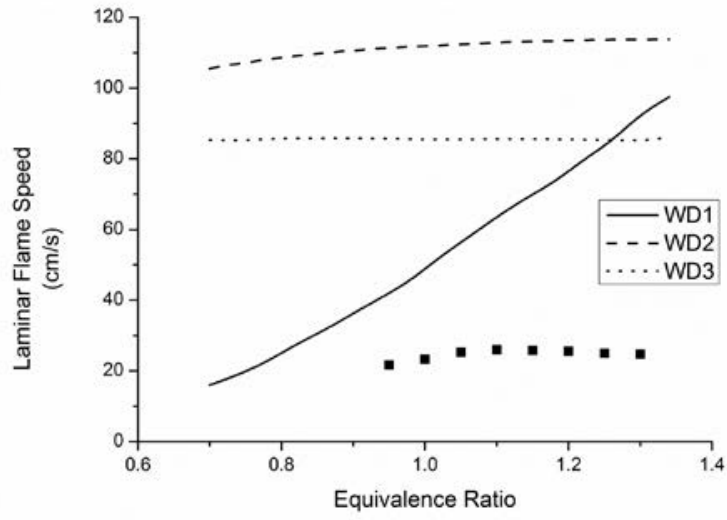

(b) WD kinetic and its modified sets

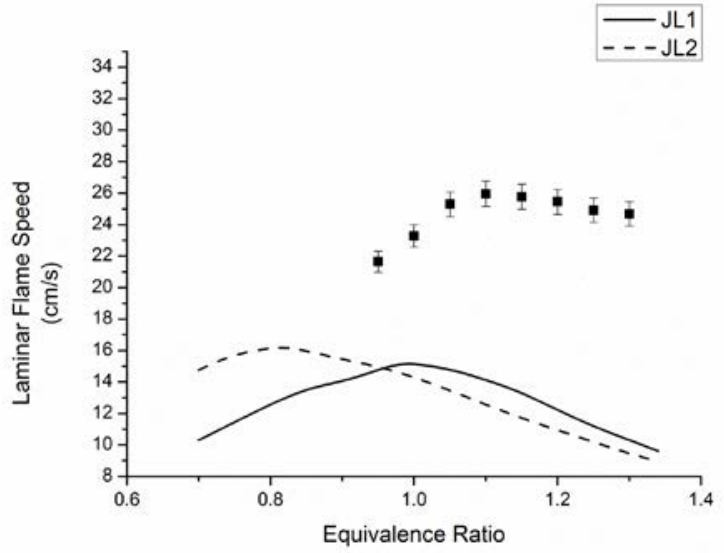

(c) JL kinetic and its modified set

Fig.3 Laminar flame speed of GBG/air flame as function of equivalence ration, at $\mathrm{P}=1 \mathrm{~atm}, \mathrm{~T}_{\mathrm{in}}=298 \mathrm{~K}$; Lines represent the calculation results achieved from chemical kinetics; Points represent the experimental measurements.

\section{Prediction of GBG/air flame speed}

Figure 3 shows the predicted results of both detailed and simplified kinetics in comparison with the experimental data as a function of equivalence ratio. The prediction from detailed kinetics, WD kinetic based sets and JL kinetic based sets are plotted in three different figures to evaluate the ability of capturing the varying trends. An error bar of around $4.1 \%$ is also plotted for the experimental data.

For two detailed kinetics, a slightly high laminar flame speed is achieved compared with the experiment data. A reasonable explanation for the over-estimation is again the adiabatic assumption that used in the simulation process. A better agreement of the laminar flame speed at the lean-side of combustion is reported in previous studies for syngas $\left(\mathrm{CO} / \mathrm{H}_{2}\right)$ flames [2]. Both kinetics are not catching the peak of laminar flame speed, however, the San Diego kinetic tends to have a closer agreement with experimental data at the fuel-rich region.

For the Westbrook and Dryer kinetic, all the original kinetic and modified kinetics are failing to predict the laminar flame speed of GBG/air flame. Where the original Westbrook and Dryer's kinetic shows a constantly growing trend of laminar flame speed. This may cause as the reason of not including the hydrogen shift reaction which has a minor effect in methane/air flame. The addition of the hydrogen shift reaction and its optimized form are still not capturing the flame speed of experimental measurements.

JL kinetic and its modified set are also unable to predict the laminar flame speed of GBG combustion. It shows a underestimation to the laminar flame speed compared with experimental data, at the same time, the peak value is moving towards the fuel-lean side.

For further validation of simplified kinetics, the comparison of temperature distribution as the function of flame propagation distance estimated through simplified and detailed calculation are shown in Fig. 4. Two simplified kinetics which are optimized for syngas diffusion flame is compared with detailed kinetic GRI 3.0 with the adiabatic free-propagation GBG/air flame at stoichiometric condition. It is clear to see that the JL2 kinetic has reached a good agreement with GRI 3.0 kinetic where the WD3 kinetic fails to predict the temperature distribution. The following optimization is therefore carried out based on the JL reaction kinetic. 


\section{Optimization of the simplified kinetic}

The predicted results by the simplified kinetics have failed to reach an appropriate agreement with both the experiment data and detailed kinetic results of GBG/air flame. Therefore, an optimization is required before the simplified kinetic to be used in CFD simulation of GBG fuel combustion.

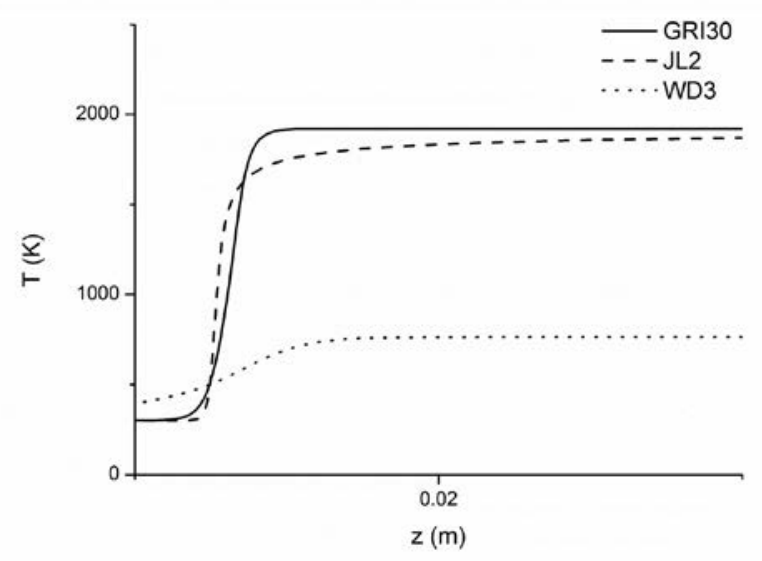

Fig. 4 Temperature distribution prediction along the flame propagating direction using different kinetics

In the previous study of hydrogen combustion, the propagation of the flame is found to be supported essentially by the diffusion $\mathrm{H}_{2}$ into flame zone and the diffusion of $\mathrm{H}$ into the pre-flame zone. The peak of laminar flame speed is shifted to higher equivalence ratio where the diffusive fluxes of $\mathrm{H}_{2}$ and $\mathrm{H}$ are higher. As in simplified reaction kinetics, the diffusion effects of various intermediates are hard to be integrated. Two dissociation reactions of water and oxygen are added to the JL kinetic for improved results of laminar flame speed. The formulation of new kinetic (JL-O kinetic) contains 6 reactions which are shown as follow:

- $\mathrm{O} 1 \mathrm{CH}_{4}+0.5 \mathrm{O}_{2} \rightarrow \mathrm{CO}+2 \mathrm{H}_{2}$

- $\mathrm{O} 2 \mathrm{CH}_{4}+\mathrm{H}_{2} \mathrm{O} \rightarrow \mathrm{CO}+3 \mathrm{H}_{2}$

- $\mathrm{O} 3 \mathrm{H}_{2}+0.5 \mathrm{O}_{2}<=>\mathrm{H}_{2} \mathrm{O}$

- $\mathrm{O} 4 \mathrm{CO}+\mathrm{H}_{2} \mathrm{O}<=>\mathrm{CO}_{2}+\mathrm{H}_{2}$

- $\mathrm{O} 5 \mathrm{O}_{2}<=>2 \mathrm{O}$

- $\mathrm{O} 6 \mathrm{H}_{2} \mathrm{O}<=>\mathrm{H}+\mathrm{OH}$

The reaction rate of $\mathrm{O} 5$ and $\mathrm{O} 6$ is calculated from detailed kinetics and reported in previous studies.

The optimization of parameters is also required to achieve a better agreement with experimental data. In the current study of GBG/air flame (CO/CO $\left./ \mathrm{H}_{2} / \mathrm{CH}_{4} / \mathrm{N}_{2}\right)$, $\mathrm{CO}$ and $\mathrm{H}_{2}$ take a large proportion of combustible material. The oxidation rate of $\mathrm{H}_{2}$ is mainly governed by reaction $\mathrm{O} 3$. The oxidation rate of $\mathrm{CO}$ is a little more complicated as it is influenced by the rate constant of reaction $\mathrm{O} 4$, as well as the reaction with water vapour which is generated by reaction $\mathrm{O} 3$.

A nonlinear optimization is carried out with minor change to original JL kinetic. The attempt to modify the reaction constant of $\mathrm{O} 4$ has a little influence to simplified laminar flame speed curve; an increase in $\mathrm{O} 4$ results in shifting the flame speed curve upwards. As the $\mathrm{CO}$ oxidation is becoming the rate limiting reaction with the formation of $\mathrm{H}_{2} \mathrm{O}$ from $\mathrm{O} 3$. The rate constant of $\mathrm{O} 3$ is optimized as well as the reversed reaction rate. The reaction of $\mathrm{O} 1$ and $\mathrm{O} 2$ are retained as the methane has minor influence in GBG fuel combustion. As the hydrocarbon reaction rates are retained, the reactions of higher hydrocarbon gases could be added to simulate the complex GBG mixture from the real industrial case.

\section{Validation of the optimized kinetic}

The reaction rate of optimized kinetic is listed in Table 5. The kinetic simulation result of laminar flame speed using optimized JL-O kinetic is compared to the results achieved from detailed kinetics simulation and experimental data are given in Fig. 5 at various inlet temperatures. It is clear that see the predicted results JL-O kinetic is showing a much better fit with the experimental data than original simplified kinetics. The optimized kinetic gives a good agreement with the detailed kinetics in the lean region. As the kinetic is specifically optimized for current study case, a better agreement with experimental data in the rich region of combustion is achieved compared to detailed reaction kinetics. An error less than 5\% percent is achieved in that case.

The validation of the JL-O kinetic were carried out by considering various inlet temperatures. The predicted results of both detailed kinetics and optimized kinetic tend to overestimate the laminar flame speed compared to experimental measurements for all inlet temperature conditions. The variation between predicted results and the experimental measurements tends to become larger with higher inlet temperature. This is expected as higher inlet temperature leads to higher heat loss in the combustion process. It is also an interesting observation that the optimized kinetic continued to maintain the closer agreement with the experimental measurements with increased inlet temperatures while the similar results predicted from detailed kinetic schemes are continuing to moving away with increased inlet temperatures.

Another observation is the non-continuous character of optimized kinetic in some range of the equivalence ratio. The reason of these "jumpy" results is due to the numerical convergence problem when using simplified reaction kinetics. Generally, the more sufficient sets of initial condition can lead to a better continuous result. But at the same time, the simulation time is increased with more rigorous criteria.

Table 5. Optimized JL kinetic for GBG/air flame

\begin{tabular}{ccccc}
\hline No & $A$ & $\beta$ & $E_{a}$ & Reaction Orders \\
\hline $\mathrm{O} 1$ & $7.820 \times 10^{13}$ & 0 & 30000 & {$\left[\mathrm{CH}_{4}\right]^{0.5}\left[\mathrm{O}_{2}\right]^{1.25}$} \\
O2 & $3.000 \times 10^{11}$ & 0 & 30000 & {$\left[\mathrm{CH}_{4}\right]\left[\mathrm{H}_{2} \mathrm{O}\right]$} \\
O3 & $9.860 \times 10^{18}$ & -1 & 36500 & {$\left[\mathrm{H}_{2}\right]^{0.3}\left[\mathrm{O}_{2}\right]^{1.5}$} \\
O3r & $5.748 \times 10^{18}$ & -0.870 & 97900 & {$\left[\mathrm{H}_{2}\right]^{-0.75}\left[\mathrm{O}_{2}\right]\left[\mathrm{H}_{2} \mathrm{O}\right]$} \\
O4 & $5.500 \times 10^{12}$ & 0 & 19300 & {$\left[\mathrm{CO}^{12}\left[\mathrm{H}_{2} \mathrm{O}\right]\right.$} \\
O5 & $2.300 \times 10^{22}$ & -3 & 120000 & {$\left[\mathrm{H}_{2} \mathrm{O}\right]$} \\
O6 & $1.500 \times 10^{09}$ & 0 & 113000 & {$\left[\mathrm{O}_{2}\right]$} \\
\hline
\end{tabular}




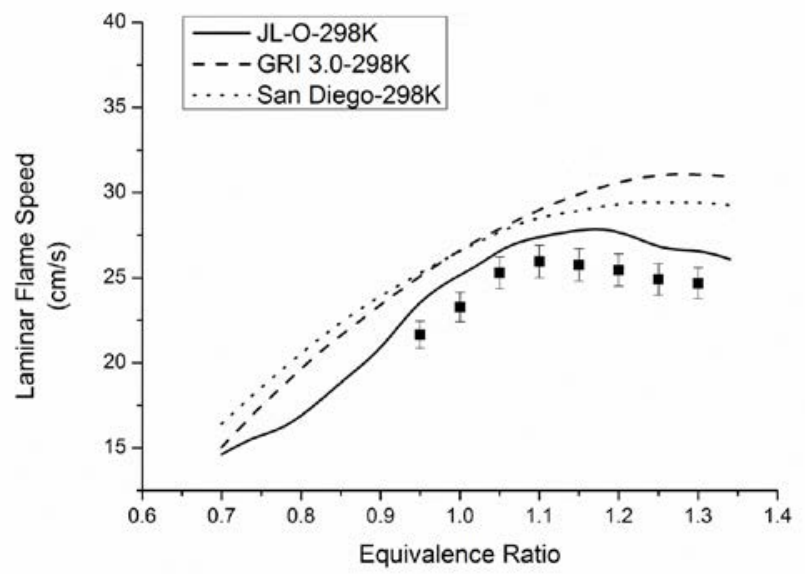

(a) $298 \mathrm{~K}$

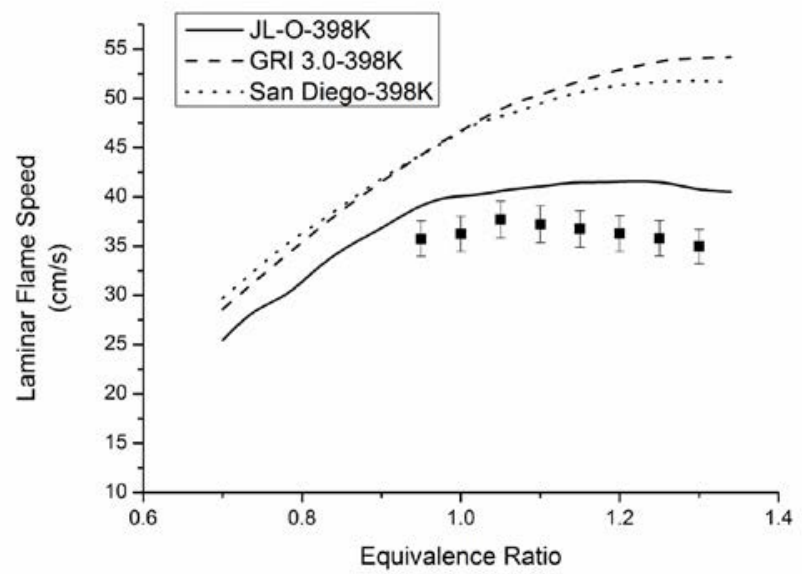

(c) $398 \mathrm{~K}$

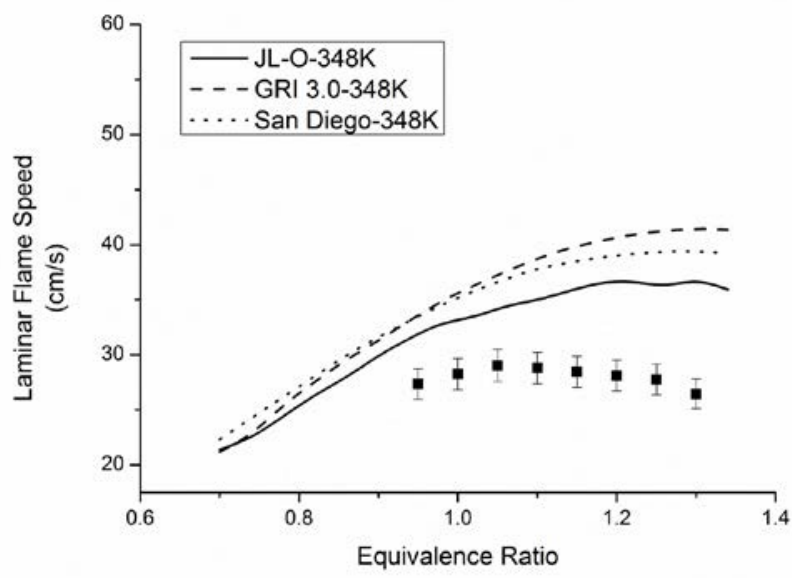

(b) $348 \mathrm{~K}$

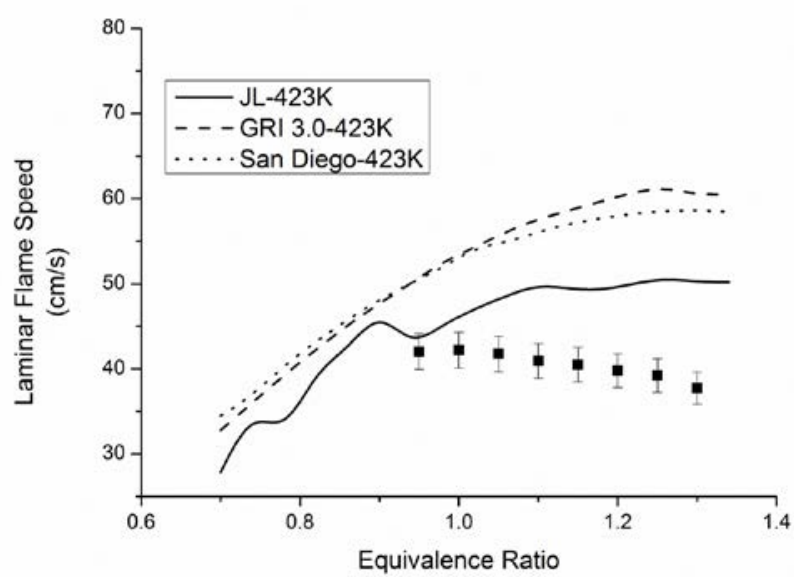

(d) $423 \mathrm{~K}$

Fig.5 Laminar flame speed of GBG/air flame as function of equivalence ratio, at $\mathrm{P}=1 \mathrm{~atm}, \mathrm{~T}_{\text {in }}=(\mathrm{a}) 298 \mathrm{~K}$, (b) $348 \mathrm{~K}$, (c) $398 \mathrm{~K}$ and (d) $423 \mathrm{~K}$ respectively; Lines represent the calculation results achieved from chemical kinetics; Points represent the experimental measurements.

\section{Validation with water vapour Injection}

Water Vapour is considered as a common byproduct in GBG fuels. The presence of water vapour in the gas composition influences the hydrogen and carbon monoxide oxidation, hence the chemical kinetic schemes considered in previous sections should be evaluated considering additional chemical reactions of water vapour. Therefore the optimized $\mathrm{JL}-\mathrm{O}$ kinetic is validated with an addition of water vapour. The results are shown in Fig. 6 to compare with the experimental data. The error between the prediction results and the experimental data is getting larger with an addition of $5 \%$ water vapour into the GBG fuel. Although the optimized kinetic gives a slightly better prediction compare to detailed kinetics, a notable feature is that the calculated value gets larger with the addition of water vapour when using the optimized kinetic. When detailed kinetics and experimental data shows a decline with the addition of water vapour. The reason of the opposite trends may due to the largely simplified reaction process and the roughly estimated reaction rate of reaction $\mathrm{O} 4$ which increases the $\mathrm{H}_{2}$ concentration from $\mathrm{CO}$ oxidation reactions.

\section{Validation with other experimental data}

Further validation of the optimized kinetic is done with the experimental data published in literature by other researchers. Two different fuel mixtures are selected to represent the typical composition of GBG fuels. Gas1 represents wood syngas used in [12] and Gas2 represents the downdraft syngas used in [33]. The composition of two mixtures is shown in Table 6.

The predicted results of the optimized and detailed kinetics are shown in Fig. 7 to compare with the comparison to experimental data. There is an underestimation of laminar flame speed from all three kinetics for Gas1. The possible reason is the higher hydrocarbon components in Gas1 such as $\mathrm{C}_{2} \mathrm{H}_{4}$ and $\mathrm{C}_{2} \mathrm{H}_{6}$ are treated as inert in kinetic simulations which cause the under-estimation. The predicted result of Gas 2 is generally good with all three kinetics. But under the rich region 


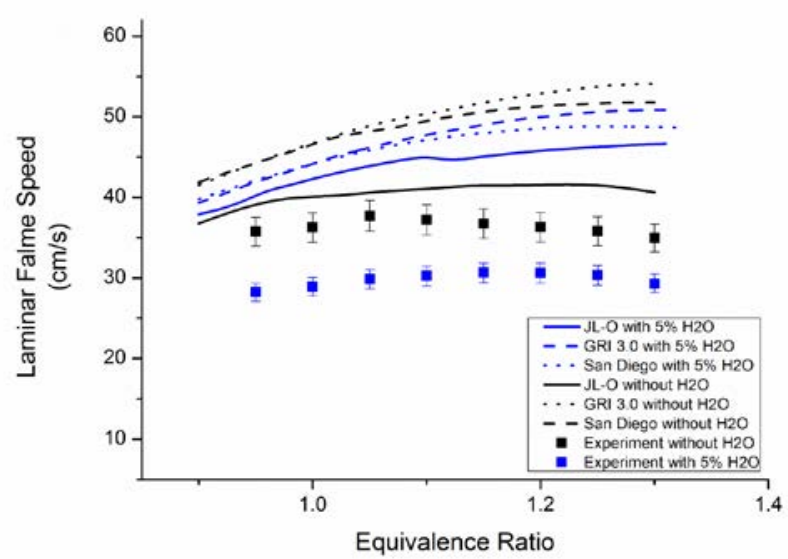

Fig.6 Laminar flame speed of GBG/air flame as function of equivalence ratio, at $\mathrm{P}=1 \mathrm{~atm}, \mathrm{~T}_{\mathrm{in}}=298 \mathrm{~K}$, Lines represent the calculation results achieved from chemical kinetics; Points represent the experimental measurements; Blue lines and points represent the case with $5 \% \mathrm{H}_{2} \mathrm{O}$.

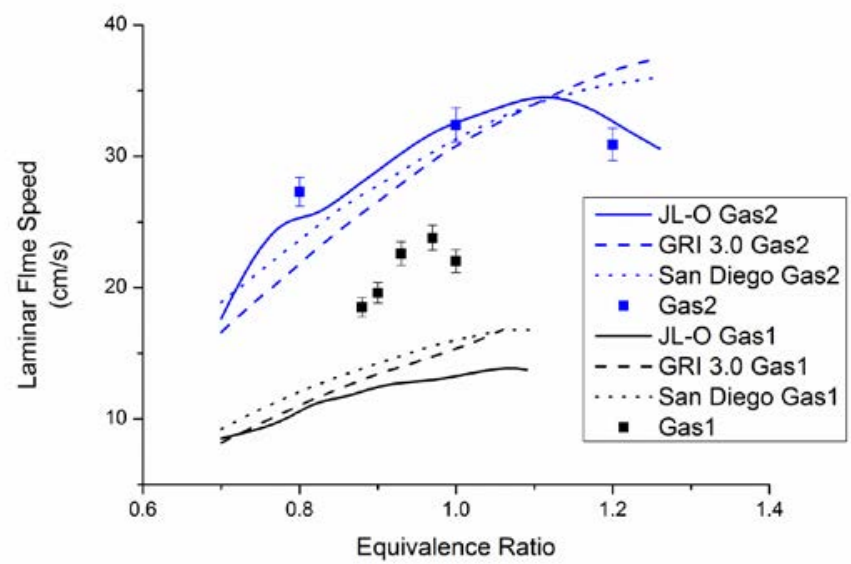

Fig.7 Laminar flame speed of two references GBG/air flame as function of equivalence ratio, at $P=1 \mathrm{~atm}, \mathrm{~T}_{\mathrm{in}}=298 \mathrm{~K}$, Lines represent the calculation results achieved from chemical kinetics; Points represent the experimental measurements.

Table 6. Gas components of references fuel mixture

\begin{tabular}{|c|c|c|c|c|c|c|c|c|c|}
\hline \multirow[t]{2}{*}{ Fuel type } & \multicolumn{8}{|c|}{ Fuel gas compositions (\% volume) } & \multirow[t]{2}{*}{$\mathrm{LHV}\left(\mathrm{MJ} / \mathrm{m}^{3}\right)$} \\
\hline & $\mathrm{CO}$ & $\mathrm{H}_{2}$ & $\mathrm{CH}_{4}$ & $\mathrm{C}_{2} \mathrm{H}_{4}$ & $\mathrm{C}_{2} \mathrm{H}_{6}$ & $\mathrm{CO}_{2}$ & $\mathrm{~N}_{2}$ & $\mathrm{O}_{2}$ & \\
\hline Gas 1 [12] & 14.241 & 10.684 & 3.538 & 1.022 & 0.190 & 14.181 & 55.191 & 0.952 & 4.95 \\
\hline Gas 2 [33] & 21.0 & 17.0 & 1.0 & 0.0 & 0.0 & 9.0 & 53.0 & 0.0 & 4.84 \\
\hline
\end{tabular}

of combustion, detailed kinetics tend to over-estimate the laminar flame speed where the optimized kinetic has a better agreement with the experiment.

\section{CONCLUSION}

Several existing simplified kinetics including original Westbrook-Dryer 2-steps kinetic, Jones-Lindstedt 4-steps kinetic and their modified versions are evaluated in current work for predicting the laminar flame speed of adiabatic GBG/air flame. The validation process is carried out by comparing the results with both the detailed reaction kinetics and experimental data from recent studies. Several conclusions are reached by the current study.

1 , As a good agreement is reached with detailed kinetic simulations and experimental data for the methane/air flame, the prediction for the GBG/air flame is less accurate with detailed kinetics. The predicted value achieved from detailed kinetic simulation generally tends to over-estimate the laminar flame speed when compared with experimental data, which may due to the adiabatic approximation that used in the simulation program. The difference of the simulated and measured results of GBG/air laminar flame speed gets wider when moves toward the rich region and higher inlet temperature.

2, For the simplified kinetics, The predicted value from Jones -Lindstedt kinetic has shown a better agreement with detailed kinetics and experimental data for the methane/air flame, when the Westbrook-Dryer kinetic has failed to predict the laminar flame speed under the rich conditions.
3, As it is evident from the simulations of simplified kinetics, it was unable to estimate the GBG/air flame speed that could be compared with experimental measurements. The JL kinetic and its modified version enormously under-estimate the laminar flame speed and shift the peak to the lean side, where the WD kinetic and its modified versions go opposite to overestimate the value and shift the peak all the way towards the rich side.

As further optimization is required for the simplified kinetics when estimating the laminar flame speed of GBG/air flames. Therefore a new set of simplified kinetic is proposed and optimized for $\mathrm{GBG}\left(\mathrm{CO} / \mathrm{H}_{2} / \mathrm{CH}_{4} / \mathrm{CO}_{2} / \mathrm{N}_{2}\right) /$ air flame. A modest result is achieved using the optimized kinetic for the current set of GBG fuel composition under a certain range of inlet temperature and equivalence ratio. The further validation with water vapour injection and different gas components has shown a certain agreement compared with detailed kinetic predictions, but has larger divergence with experimental data. However, the robustness of the optimized kinetic still needs to be tested before to be used in practice of CFD simulations. The feasibility of the optimized kinetic remains uncertain due to lack of experimental data.

\section{NOMENCLATURE}

- GBG: gasified biomass gas

- CFD: computational fluid dynamics

- A: pre-exponential factor

- $\quad \beta$ : unitless number of order 1

- $E_{a}$ : activation energy 
- $r_{b}$ : backward reaction rate

- $\quad k_{f}$ : forward reaction rate constant

- $K_{e q}$ : equilibrium constant

- $S_{b}$ : flame speed of burned mixture, $\mathrm{m} / \mathrm{s}$

- $S_{u}$ : flame speed of unburned mixture, $\mathrm{m} / \mathrm{s}$

- $\rho_{b}$ : density of burned mixture, $\mathrm{kg} / \mathrm{m}^{3}$

- $\rho_{u}$ : density of unburned mixture, $\mathrm{kg} / \mathrm{m}^{3}$

- $\quad \dot{m}$ : mass flow rate of the unburned mixture, $\mathrm{kg} / \mathrm{s}$

- $\quad \dot{v}$ : volumetric flow of the unburned mixture, $\mathrm{kg} / \mathrm{s}$

- $T_{i n}$ : Fuel gas inlet temperature

\section{ACKNOWLEDGEMENT}

The research has been funded by the Chinese Scholarship Council and the Royal Institute of Technology, the support of which is gratefully acknowledged.

\section{REFERENCES}

[1] Munajat, N. F., Erlich, C., Fakhrai, R., and Fransson, T. H., 2012, "Influence of Water Vapour and Tar Compound On Laminar Flame Speed of Gasified Biomass Gas," Applied Energy, 98, pp. 114-121.

[2] Tabatabaei, A. F. and Soroudi, M. A., "A Kinetic Study of Syngas Combustion Characteristics for Gas Turbine Applications,".

[3] Abou-Taouk, A. and Eriksson, L. E., 2011, "Optimized Global Mechanisms for Cfd Analysis of Swirl-Stabilized Syngas Burner for Gas Turbines", ASME Paper, GT2011-45853.

[4] Boivin, P., Jim E Nez, C., S A Nchez, A. L., and Williams, F. A., 2011, "A Four-Step Reduced Mechanism for Syngas Combustion," Combustion And Flame, 158 (6), pp. 1059-1063.

[5] Yan, B., Wu, Y., Liu, C., Yu, J. F., Li, B., Li, Z. S., Chen, G., Bai, X. S., Aldén, M., and Konnov, A. A., 2011, "Experimental and Modeling Study of Laminar Burning Velocity of Biomass Derived Gases/Air Mixtures," International Journal Of Hydrogen Energy, 36 (5), pp. 3769-3777.

[6] He, Y., Wang, Z., Yang, L., Whiddon, R., Li, Z., Zhou, J., and Cen, K., 2012, "Investigation of Laminar Flame Speeds of Typical Syngas Using Laser Based Bunsen Method and Kinetic Simulation," Fuel, 95, pp. 206-213.

[7] Westbrook, C. K. and Dryer, F. L., 1984, "Chemical Kinetic Modeling of Hydrocarbon Combustion," Progress In Energy And Combustion Science, 10 (1), pp. 1-57.

[8] Olson, D. B. and Gardiner Jr., W. C., 1978, "Combustion of Methane in Fuel-Rich Mixtures," Combustion And Flame, 32, pp. 151161.

[9] Dixon-Lewis, G. and Williams, D. J., 1977, "Chapter 1 the Oxidation of Hydrogen and Carbon Monoxide," Vol 17, pp. 1-248.

[10] Dryer, F. L. and Chaos, M., 2008, "Ignition of Syngas/Air and Hydrogen/Air Mixtures at Low Temperatures and High Pressures:
Experimental Data Interpretation and Kinetic Modeling Implications," Combustion And Flame, 152 (1-2), pp. 293-299.

[11] Westbrook, C. K., Pitz, W. J., Herbinet, O., Curran, H. J., and Silke, E. J., 2009, "A Comprehensive Detailed Chemical Kinetic Reaction Mechanism for Combustion of N-Alkane Hydrocarbons From N-Octane to N-Hexadecane," Combustion And Flame, 156 (1), pp. 181-199.

[12] Ouimette, P. and Seers, P., 2009, "Numerical Comparison of Premixed Laminar Flame Velocity of Methane and Wood Syngas," Fuel, 88 (3), pp. 528-533.

[13] Petrova, M. V. and Williams, F. A., 2006, "A Small Detailed Chemical-Kinetic Mechanism for Hydrocarbon Combustion," Combustion And Flame, 144 (3), pp. 526-544.

[14] Stefanidis, G. D., Merci, B., Heynderickx, G. J., and Marin, G. B., 2006, "Cfd Simulations of Steam Cracking Furnaces Using Detailed Combustion Mechanisms," Computers $1 \&$ Chemical Engineering, 30 (4), pp. 635-649.

[15] Saxena, P. and Williams, F. A., 2006, "Testing a Small Detailed Chemical-Kinetic Mechanism for the Combustion of Hydrogen and Carbon Monoxide," Combustion And Flame, 145 (1), pp. 316-323.

[16] Fernández-Galisteo, D., Sánchez, A. L., Liñán, A., and Williams, F. A., 2009, "One-Step Reduced Kinetics for Lean Hydrogen-Air Deflagration," Combustion And Flame, 156 (5), pp. 985-996.

[17] Kim, J. P., Schnell, U. and Scheffknecht, G., 2008, "Comparison of Different Global Reaction Mechanisms for Mild Combustion of Natural Gas," Combustion Science And Technology, 180 (4), pp. 565592.

[18] Zs E Ly, I. G., Nagy, T., Simmie, J. M., and Curran, H. J., 2009, "Reduction of a Detailed Kinetic Model for the Ignition of Natural Gas Mixtures at Gas Turbine Conditions", eds.,pp.

[19] Di Mare, F., Jones, W. P. and Menzies, K. R., 2004, "Large Eddy Simulation of a Model Gas Turbine Combustor," Combustion And Flame, 137 (3), pp. 278-294.

[20] Jones, W. P. and Lindstedt, R. P., 1988, "Global Reaction Schemes for Hydrocarbon Combustion," Combustion And Flame, 73 (3), pp. 233-249.

[21] Cuoci, A., Frassoldati, A., Faravelli, T., and Ranzi, E., 2009, "Accuracy and Flexibility of Simplified Kinetic Models for Cfd Applications", $32^{\text {nd }}$ Annual Meeting of the Italian Section of the Combustion Institute

[22] Cheng, T. S., Chang, Y. C., Chao, Y. C., Chen, G. B., Li, Y. H., and Wu, C. Y., 2011, "An Experimental and Numerical Study On Characteristics of Laminar Premixed H2/Co/Ch4/Air Flames," International Journal Of Hydrogen Energy, 36 (20), pp. 13207-13217.

[23] Das, A. K., Kumar, K. and Sung, C., 2011, "Laminar Flame Speeds of Moist Syngas Mixtures," Combustion And Flame, 158 (2), pp. 345-353. 
[24] Vu, T. M., Song, W. S., Park, J., Bae, D. S., and You, H. S., 2011, "Measurements of Propagation Speeds and Flame Instabilities in Biomass Derived Gas-Air Premixed Flames," International Journal Of Hydrogen Energy, 36 (18), pp. 12058-12067.

[25] Liu, C., Yan, B., Chen, G., and Bai, X. S., 2010, "Structures and Burning Velocity of Biomass Derived Gas Flames," International Journal Of Hydrogen Energy, 35 (2), pp. 542-555.

[26] Bouvet, N., Chauveau, C., Gökalp, I., Lee, S. Y., and Santoro, R. J., 2011, "Characterization of Syngas Laminar Flames Using the Bunsen Burner Configuration," International Journal Of Hydrogen Energy, 36 (1), pp. 992-1005.

[27] Dryer, F. L. and Glassman, I., 1973, "High-Temperature Oxidation of $\mathrm{CO}$ and $\mathrm{CH}_{4}$ ", 14, pp. 987-1003.

[28] CHARLES, K. W. and Dryer, F. L., 1981, "Simplified Reaction Mechanisms for the Oxidation of Hydrocarbon Fuels in Flames," Combustion Science And Technology, 27 (1-2), pp. 31-43.

[29] Franzelli, B., Riber, E., Sanjos E, M., and Poinsot, T., 2010, "A Two-Step Chemical Scheme for Kerosene--Air Premixed Flames," Combustion And Flame, 157 (7), pp. 1364-1373.

[30] Smith, G. P., Golden, D. M., Frenklach, M., Moriarty, N. W., Eiteneer, B., Goldenberg, M., Bowman, C. T., Hanson, R. K., Song, S., Gardiner Jr, W. C., and Others, 1999, "Gri-Mech 3.0," URL: http://www. me. berkeley. edu/gril_mech.

[31] "Chemical-Kinetic Mechanisms for Combustion Applications", . San, Diego Mechanism Web, Mechanical and Aerospace Engineering (Combustion Research), University of California at San Diego (http://combustion.ucsd.edu).

[32] Dong, C., Zhou, Q., Zhao, Q., Zhang, Y., Xu, T., and Hui, S., 2009, "Experimental Study On the Laminar Flame Speed of Hydrogen/Carbon Monoxide/Air Mixtures," Fuel, 88 (10), pp. 18581863.

[33] Monteiro, E., Bellenoue, M., Sotton, J., Moreira, N. A., and Malheiro, S., 2010, "Laminar Burning Velocities and Markstein Numbers of Syngas-Air Mixtures," Fuel, 89 (8), pp. 1985-1991.

[34] D. Goodwin, "Cantera: An object-oriented software toolkit for chemical kinetics, thermodynamics, and transport processes", Caltech, Pasadena, 2009. [Online]. Available: http://code.google.com/p/cantera 